Bull. Géod., 1958, No. 49, pp. 67-74. Pergamon Press Ltd.

CHRONIQUE INTERNATIONALE

ÉTATS-UNIS

\title{
GUENTER LOESER MEMORIAL LECTURE
}

The Geophysics Research Directorate, Air Force Cambridge Research Center, Bedford, Mass. announces the selection of Mrs. Rita C. SAGalyn as Guenter Loeser Memorial Lecturer for 1958. Mrs. SAGALYN will speak on 'Recent Investigations of Electrical Phenomena in the Atmosphere'. The lecture will be delivered at 2.00 p.m., 4 June 1958, in the Charter Room of the New England Mutual Building, Boston, Mass.

The Guenter Loeser Memorial Lecture is given at intervals of one year or more by a scientist of the Geophysics Research Directorate who is nominated in recognition of outstanding achievement in research.

Mrs. Sagalyn is a native of Lowell, Mass. During World War Two, she worked at the M.I.T. Radiation Laboratory, studying the performance characteristics of magnetrons. Her studies at M.I.T. helped enable her to obtain, in 1948, the B.S. degree in physics from the University of Michigan in three-years time. While at Michigan, she was honored as University Scholar and worked in the Physics Laboratories on problems of infrared and physical electronics. In 1950, she was awarded the M.A. degree by Radcliffe College. Mrs. Sagalyn has been a member of the Geophysics Research Directorate since 1950 where she has attained an outstanding reputation for her work concerning the electrical phenomena of the atmosphere.

The Guenter Loeser Memorial Lecture is a direct tribute to a distinguished scientist who was killed in 1953 while engaged in a meteorological research aircraft flight. In $1954 \mathrm{Dr}$. LOESER's friends and colleagues conceived of this lecture as a lasting memorial. The honor to deliver the lecture has previously been awarded to Dr. JEAN I. F. KING in 1955, Dr. RoberT G. Breene, JR. in 1956, and Dr. David Atlas in 1957.

\section{ÉTATS-UNIS}

\section{AMERICAN CONGRESS ON SURVEYING AND MAPPING AMERICAN SOGIETY OF PHOTOGRAMMETRY CONSEGUTIVE MEETINGS OF 1958}

This year for the fourth time Consecutive Meetings and a Co-exhibit of the American Congress on Surveying and Mapping and the American Society of Photogrammetry were held in Washington, D.C. The meetings 